Article

\title{
Exploring the "Energy-Saving Personality Traits" in the Office and Household Situation: An Empirical Study
}

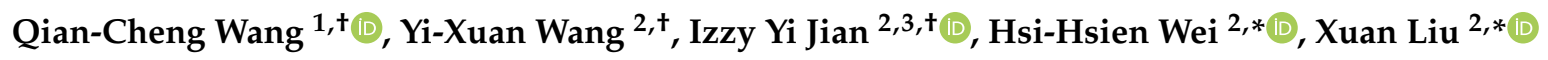 \\ and Yao-Tian $\mathrm{Ma}^{4}$ \\ 1 Department of Land Economy, University of Cambridge, Cambridge CB3 9EP, UK; qw250@cam.ac.uk \\ 2 Department of Building and Real Estate, The Hong Kong Polytechnic University, Hong Kong 518000, China; \\ wendyyixuan.wang@connect.polyu.hk (Y.-X.W.); yi.jian@connect.polyu.hk (I.Y.J.) \\ 3 Research Institute of Sustainable Urban Development, The Hong Kong Polytechnic University, \\ Hong Kong 518000, China \\ 4 Department of Architecture, University of Cambridge, Cambridge CB2 1PX, UK; my361@cam.ac.uk \\ * Correspondence: hsi-hsien.wei@polyu.edu.hk (H.-H.W.); irene.l.liu@connect.polyu.hk (X.L.) \\ + These authors contributed equally to this study.
}

Received: 11 May 2020; Accepted: 6 July 2020; Published: 9 July 2020

\begin{abstract}
Behavior-driven energy conservation has been a promising strategy for reducing building energy consumption as well as carbon emissions. With the intention of revealing the impacts of an individual's personality basis on energy conservation behavioral attitudes and intentions in households and offices, the present study proposes and conducts an experiment in Xi'an, China with two groups for the investigation of such attitudes towards household energy-saving behavior (HESB) and office energy-saving behavior (OESB), respectively. The research adopts structural equation modeling for experiment data analysis. The analysis results suggest that the two personality traits, Agreeableness and Neuroticism, are significantly related to both HESB and OESB attitudes. Especially, agreeable people tend to present stronger energy-saving attitudes, while individuals with higher Neuroticism are less likely to do so. The results indicate that the impacts of these two traits on energy-saving attitude are found to be less influenced by different environment settings. Further, the results find that Extraversion positively influences energy-saving attitude in the office environment, while Openness only significantly works in the household environment. It is hoped that the findings of the present study can provide informative references to energy-saving intervention design as well as further studies on the spillover of pro-environmental behaviors.
\end{abstract}

Keywords: energy-saving; attitude; Big Five; personality traits; office; household; pro-environment

\section{Introduction}

Energy security plays a critical role in social, economic and environmental development [1]. An adequate energy supply can not only reduce the risk of political extortion, but also control the cost of industrial development. Besides, energy consumption is closely related to greenhouse gas (GHG) emissions as well as a series of environmental pollution. In addition to developing novel energy-efficient techniques [2], in the last few decades, governments have paid much attention to efficient energy consumption and resource conversation. More and more governments implement policies to encourage business owners and households to use equipment with higher energy efficiency. The European Union, for example, has set up several directives and projects to reduce energy consumption by $20 \%$ [3]. Through these energy policies, these countries or regions have not only reduced their dependence on energy imports, but also effectively promoted environmental sustainability. 
Pro-environmental behaviors (PEBs) refer to "individual behaviors to enhance environmental sustainability" [4]. Promoting energy conservation and other PEBs seems a promising strategy for sustainable development: compared with other means [5], behavior-driven approaches generally work with less initial investments and quick returns [6]. Behavior-driven energy-saving solutions have been well considered in several green building schemes [7]. PEBs can be predicted by some psychological and demographic items [8-10]. The theory of personality trait, for example, explains the highly stable individual differences in PEB intentions [11,12]. Personality traits refer to factors reflecting individual characteristic patterns of thoughts as well as feelings and further reflecting individual behavioral patterns [13]. Personality traits might influence one's attitude towards PEBs [14-16], and then further contribute to sustainable intentions and behaviors directly or indirectly $[17,18]$. Some studies support that people with some specific personality characteristics (so-called "green personalities") tend to present stronger attitudes towards PEBs and have more environmental protection potential [12]. This is also in line with some studies on PEB spillover: people performing one PEB have higher likelihoods of performing other PEBs $[19,20]$. Based on the personality trait theories, research works have further made use of personality characteristics as well as interventions in PEB promotion [21,22].

However, there is growing evidence that people may present different intentions towards different PEBs and in different environments [9,23]. Wells et al. [9], for example, found the spillover effect of different resource conservation behaviors in different situations less significant. Especially, people present a remarkable difference between their PEB intention inside and outside their homes. Tudor et al. [24] also reported the connections and differences between PEBs at work and at home, which supported the above statement. Besides, people with similar personality characteristics might present individual differences in different PEBs. For example, Tang and Lam [25] noted that agreeable people who consider more about others' feelings are more likely to pay for green hotels consuming less energy and resources. However, Kamal and Barpanda [26] found that not agreeable but extroverted students tend to save energy at school. Shen et al. [27] found the contribution of both of the above two personality traits to household energy-saving behavior (HESB) insignificant. Thorough understanding of the individual difference in energy-saving attitudes and intentions at different situations is important for effective energy policy-making as well as energy-saving intervention development. Thus, it is necessary to reveal the contribution of "energy-saving personality traits" to the mentioned individual differences.

This study aims to reveal the personality basis of individual differences in attitudes as well as intentions towards energy conservation inside and outside the family environment. There are only a few pro-environmental behavior studies focusing on the developing areas. To bridge this gap, this study, however, conducts the field experiment with 800 participants in Xi'an, a typical city in the northwest region, the most undeveloped area in China. Participants are divided into two groups focusing on HESB and office energy-saving behavior (OESB), respectively. HESB is a typical respective of in-home pro-environmental behavior (IHPEB), which refers to "individual actions for environmental protection at households or private spaces". OESB represents out-of-home pro-environmental behavior (OHPEB), which refers to "individual actions for pro-environmental purpose in public spaces". The study first reviews the recent literature on the relationship between personality traits and PEBs in different situations and introduces the design and conduct process of the experiment in detail. This research then analyzes the experiment data with the structural equation modeling (SEM) technique. Based on the analysis results, the paper discusses the potential causes of the results, the policy implications of the findings and the limitations of this study. This study investigates the influence of personality traits on energy-saving attitude in office and household environments. The findings of this study would provide a personality explanation of the individual differences in energy conservation attitudes in different situations. The findings would be helpful in energy-saving intervention and policy-making.

\section{Literature Review}

Broadly speaking, personality traits refer to the highly stable, individual characteristic set of behaviors, cognitions and emotional patterns that evolve from biological and environmental factors [28]. 
Personality traits can influence attitude directly [29]. Several studies have provided sufficient evidence supporting the significant contribution of personality traits to PEBs directly [30] or mediated by attitude [12,31].

The Big Five personality trait theory (also called Five-Factor Model of Personality, FFM) is one of the most commonly used models in the psychological field [32]. The FFM comprises five personality traits: Extraversion (E), Agreeableness (A), Conscientiousness (C), Neuroticism (N) and Openness $(\mathrm{O})$. Extraversion refers to the individual tendency to be outgoing, energetic and assertive to the outer world [33]. Thus, extraverted individuals often present a positive attitude to social connection engagement and show the ability to garner energy from socializing. Agreeableness is a trait manifesting itself in individual behavioral characteristics that are perceived as kind, sympathetic and cooperative [34]. Agreeableness individuals are caring for the well-beings of others and present strong humility and trustfulness. Besides, Conscientiousness is defined as the tendency of being organized and obeying obligations and goals [34]. Therefore, Conscientiousness individuals are more likely to accomplish assigned tasks and respect for the disciplines that encourage organizational achievements [35]. Neuroticism refers to the individual tendency to experience negative emotions [34]. Individuals with higher scores on Neuroticism tend to present lower emotional stability. Openness is the tendency to embrace knowledge, interest in generating novel configurations within practices and appreciation for variety thinking and experiences.

The literature so far critically employed the FFM in the field of PEBs, such as energy-saving [27,36,37], recycling [38], paying for green hotels [25] and sustainable tourism [31,39]. Additionally, there are several studies connecting the Big Five personality traits with PEB-related psychological factors. For instance, some previous studies linked Big Five personality traits to attitude towards PEBs $[14,15,40]$.

Considerable efforts have also been made to explore the impacts of personality traits on the IHPEBs. Several studies indicate that Agreeableness, Conscientiousness as well as Openness are potentially related to attitude and intention towards household PEBs. Markowitz et al. [17], for example, found significant relationships between the three personality traits (i.e., Agreeableness, Conscientiousness and Openness) and the HESB intention. Busic-Sontic and Brick [41] noted that individuals with higher Openness tend to accept green household installations in the UK, which is also supported by He and Veronesi's [42] study on household renewable energy technology adoption in mainland China. Shen et al. [27] argued that Conscientiousness presents the most consistency in its correlation with HESB, and Agreeableness and Openness also present positive contributions. Swami et al. [43] and Zhang et al. [44] believe that Conscientiousness is an important predictor of household waste management behavior. However, empirical findings are inconsistent. For example, both Brick and Lewis [12] and White and Hyde [45] found the relationship between Conscientiousness and household pro-environmental behavior less significant. Further, Swami et al. [43] suggested that the link between Agreeableness and in-home waste management is insignificant. The roles of Extraversion and Neuroticism, the other two personality traits, in the in-home PEB process seem unclear. Limited evidence suggested that Neuroticism is weakly but positively related to household sustainable installation behavior while the contribution of Extraversion presents as negative [41]. Individuals with high Extraversion scores are more likely to turn off lights when nobody is at home. The same law applies to individuals with lower Neuroticism [27].

Further, several personality studies focus on the OHPEBs. There is growing evidence showing that Agreeableness and Extraversion potentially contribute to out-of-home PEBs. For instance, Sun et al. [15] and Luchs [46] indicate that both Agreeableness and Extraversion positively affect the attitude towards green buying. This is in unison with the conclusion of Tang and Lam [25] who provide empirical evidence confirming the positive relationship when examining people's willingness to pay for green hotels. Yazdanpanah and Hadji Hosseinlou [47] found that extraverted people are more likely to choose public transport means. They, together with agreeable individuals, tend to present higher acceptability of sustainable transport policies, where higher levels of trust in the government would be a potential explanation [48]. Kvasova [39] indicates that both Agreeableness and Extraversion 
positively contribute to pro-environmental tourist behaviors in Cyprus. However, there also exist some different statements. For example, Passafaro et al.'s study [31] on sustainable tourism found that neither Extraversion nor Agreeableness directly contributes to pro-environmental attitudes or OHPEBs.

Yet, there exists little consensus about the relationships between the other three traits (i.e., Openness, Neuroticism and Conscientiousness) and the OHPEBs. Sun et al. [15] found that Openness and Conscientiousness also positively contribute to green consumption intention. Yazdanpanah and Hadji Hosseinlou [47] noted that Neuroticism presents a negative relationship with public transport choosing intention while the contributions of Agreeableness, Openness and Conscientiousness seem insignificant. Kvasova [39] noted that Neuroticism and Conscientiousness are positively associated with green tourist behavior while the link between Openness and the OHPEB is less significant. Chiang et al. [49] found that emotional stability positively contributes to OHPEBs. These findings highlight the complex attribute of personality traits. Further investigations on the roles of the above-mentioned three traits are necessary.

Previous research has well explored the role of the Big Five personality traits in pro-environmental attitudes and behaviors. Many studies have thoroughly analyzed the impacts of personality traits on various typical environmental-friendly attitudes or behaviors such as garbage recycling, saving resources and purchasing green products. The results of these studies indicate that personality traits have different influences on different environmental-friendly behaviors. For example, in three personality studies on energy conservation behavior, Shen et al. [27], Tiefenbeck et al. [50] and Markowitz et al. [17] presented different findings with different backgrounds. Further, participants in two studies on recycling, by Poškus and Žukauskienè [38] and Swami et al. [43], also present different attitudes with different environments (i.e., school and family). These findings show that the role of personality traits on the same pro-environment behavior in different environments might be different, thus requiring further explorations. However, there is only a limited number of studies focusing on the energy-saving attitudes in different environments and their personality explanation. Based on the above literature review, this study aims to reveal the personality basis of individual differences in energy-saving attitude in family and office environments. The researchers propose a theoretical framework connecting the Big Five personality traits with PEB intentions via attitudes. Further, the study puts several hypotheses forward on HESB and OESB, respectively. These hypotheses are shown in Table 1.

Table 1. The hypotheses put forward in the study.

\begin{tabular}{cc}
\hline & Hypothesis \\
\hline $\mathrm{H}_{1}$ & Agreeableness contributes to HESB by positively affecting attitude towards HESB \\
$\mathrm{H}_{2}$ & Conscientiousness contributes to HESB by positively affecting attitude towards HESB \\
$\mathrm{H}_{3}$ & Openness contributes to HESB by positively affecting attitude towards HESB \\
$\mathrm{H}_{4}$ & Extraversion contribute to HESB by negatively affecting attitude towards HESB \\
$\mathrm{H}_{5}$ & Neuroticism contribute to HESB by negatively affecting attitude towards HESB \\
$\mathrm{H}_{6}$ & Agreeableness contributes to HESB by positively affecting attitude towards OESB \\
$\mathrm{H}_{7}$ & Conscientiousness contributes to HESB by positively affecting attitude towards OESB \\
$\mathrm{H}_{8}$ & Openness contributes to HESB by positively affecting attitude towards OESB \\
$\mathrm{H}_{9}$ & Extraversion contribute to HESB by negatively affecting attitude towards OESB \\
$\mathrm{H}_{10}$ & Neuroticism contribute to HESB by negatively affecting attitude towards OESB \\
\hline
\end{tabular}

The hypotheses and relationships between variables in the research framework are presented graphically in Figure 1. Figure 1a shows the research model for HESB, while Figure 1b shows the research model for OESB. 


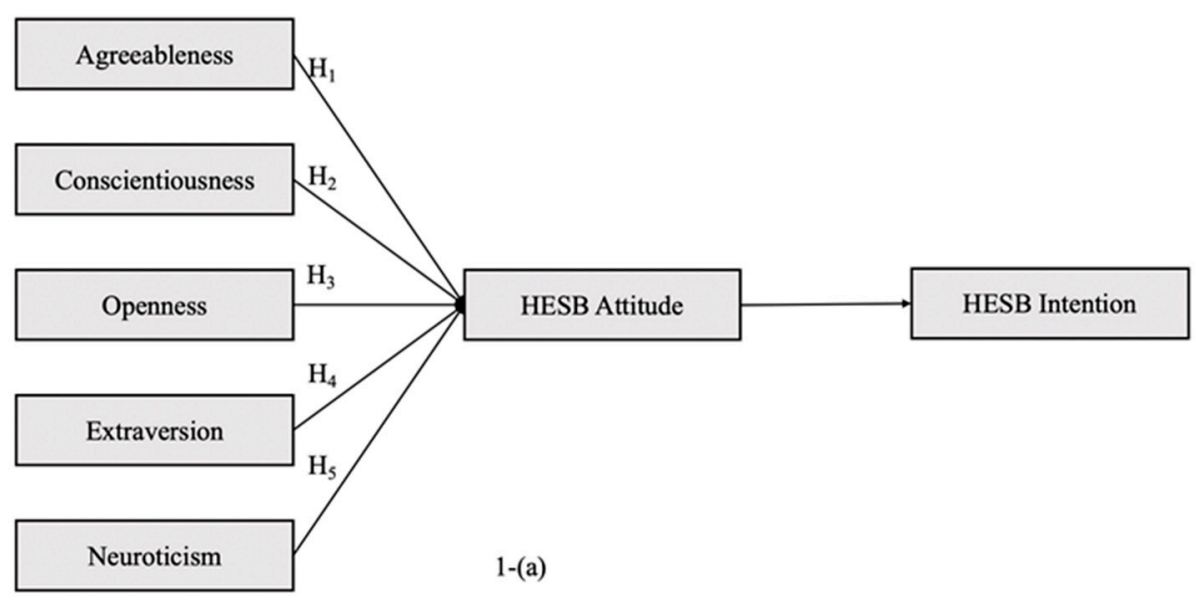

(a)

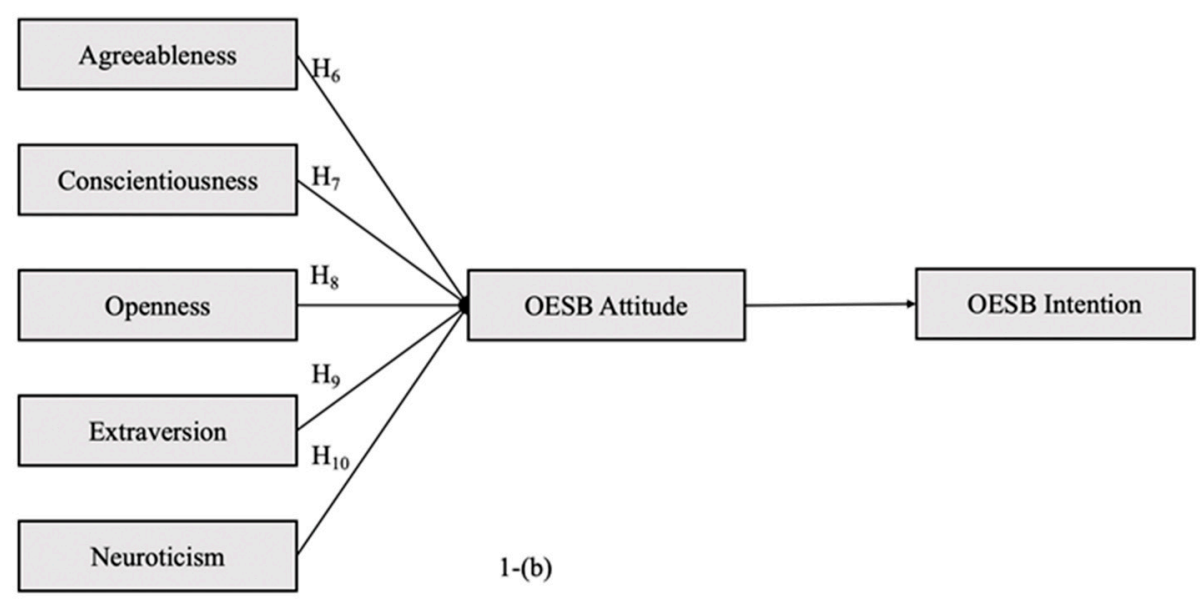

(b)

Figure 1. The research model. (a) The research model for HESB; (b) The research model for OESB.

\section{Methodology}

\subsection{Study Overview}

This research conducted a field experiment in $\mathrm{Xi}^{\prime}$ an, one of the most densely populated cities located in Shaanxi Province, northwest China, and selected two typical residential communities in Yan-Ta district (urban area in $\mathrm{Xi}^{\prime}$ an) as the study areas. Notably, these two communities are located in the same district and the residents in the selected study areas share similar socioeconomic characteristics. Especially, the participants have similar cultural and economic backgrounds as well as a built surrounding environment. Before substantial data gathering, the researchers invited five experts to review as well as revise the questionnaire in terms of its structure, wording and comprehensibility to make sure the questionnaire was understandable for the general public. These experts included two researchers in psychology, two experienced community workers in the study areas, as well as one property manager. The revised questionnaire was pilot-tested by 30 individuals to give revision suggestions to the final version of the questionnaire.

In this study, the community workers played the role as the gatekeeper. The study used the two-stage sampling method. Residents in the selected communities were encouraged to participate in this research by the staff in the neighborhood committee via a Wechat group to maximize the sample size. The researchers called for participants in the study areas through the local residential committee and there were 853 households signed-up. The researchers selected 800 households from the signed-up 
group. The selection was based on two standards: (1) the participant had lived in the investigation sites for at least six months; and (2) the participant had a steady job and had worked at the current company for at least six months so that they are familiar enough with the environments.

The participants in the experiment were purposely divided into two groups (i.e., Group A and Group B) according to their sociodemographic backgrounds to maximize the representativeness of the diverse background and to reduce the possibility of sampling bias. The respondents in different groups were required to complete the different questionnaires with different themes. The first version of the questionnaire concerns HESB (so called HESB-Q) and was prepared for Group A. The second version of the questionnaire concerns OESB (so called OESB-Q) and was prepared for Group B.

The responses from the participants were collected during January to March 2020. Due to the coronavirus (i.e., COVID-19) outbreak in China, the researchers adopted online tools to avoid face-to-face interaction from late January. Especially, the researchers employed Wechat, one of the most popular instant message Apps for consumer smart devices (i.e., smart phones and tablets) in China, to distribute the questionnaire and to collect the responses. The high usage rate makes Wechat (7.0.12, Tencent, Shenzhen, China) a suitable tool to approach potential participants in Chinese cities [8,43,51]. Sun et al. [51] provide sufficient evidence showing the feasibility of questionnaire distribution with Wechat. In this study, potential respondents were sent the online questionnaire which is able to be opened by clicking the link or scanning a QR-code on a prepared survey card to reach the online questionnaire. The structural equation modeling (SEM) approach is then adopted to delineate the causal mechanisms and numerous relationships between personality traits and different types of energy-saving behaviors in this study.

\subsection{Questionnaire Design}

Based on an extensive review of the relevant literature [6,52,53], the questionnaire survey was chosen as the main data instrument to solicit the opinions on the subject matter. In order to encourage participation, the questionnaire was completely anonymous and voluntary, respondents were assured of the confidentiality of their data [54]. No reminder letter was sent to the respondents during the data collection process. Vouchers were given to participants who completed the questionnaire and provided valid feedback successfully. Both of the questionnaires for Group A and Group B encapsulated three sections.

The first sections in the two versions are the same, where the researchers employed the Chinese version of the Ten-Item Personality Inventory (i.e., TIPI-C) to evaluate the personality characteristics of the participants. The TIPI is a short inventory for the Five-Factor Personality assessment with only 10 items. The TIPI inventory was developed by Gosling, Rentfrow and Swann [34] and has been widely employed in psychological studies on PEBs [17,55]. Lavelle-Hill et al. [56], for example, employed the TIPI in a study on plastic bag consumption. In addition, Komatsu and Nishio [37] also adopted the Japanese version of the TIPI in a study on HESB. There are several studies on the validity and reliability of the Chinese form of TIPI [57,58]. All items in the first section used a 5-point Likert rating scale (i.e., 1 = Strongly Disagree, $2=$ Disagree, $3=$ Neutral, $4=$ Agree, $5=$ Strongly Agree).

In the second section, the two questionnaires focus on the attitudes towards household and office energy-saving behavior, respectively. Each of them includes four items using the 5-point Likert rating scale. The items employed in the questionnaires for the two groups are presented in Table 2. Besides, the researchers also provided a clear definition of energy-saving behaviors as well as some typical HESBs and OESBs (see Table 3) to the participants. The HESB-Q categorizes sixteen typical HESBs into four family scenes: kitchen, living room, bedroom and bathroom. The OESB-Q categorizes nine typical HESBs into two office scenes: office desk and pantry. The questionnaires then tested the energy-saving behavioral intentions of the participants in different scenes. Different from the first section, the items as well as the checklist in this section are original.

The final section was designed to collect the socio-demographic characteristics of the respondents. The items in the third section include questions about gender, age, education level and income level. 
Table 2. The items in Section 2 of the Uniform Questionnaire

\begin{tabular}{|c|c|c|c|}
\hline Version & Group & Item & Code \\
\hline \multirow{3}{*}{ HESB-Q } & \multirow{3}{*}{ A } & HESBs are valuable for environmental protection; & ATT-1A \\
\hline & & HESBs are important for environmental protection; & ATT-2A \\
\hline & & HESBs are wise actions; & ATT-3A \\
\hline \multirow{3}{*}{ OESB-Q } & \multirow{3}{*}{ B } & OESBs are valuable for environmental protection; & ATT-1B \\
\hline & & OESBs are important for environmental protection; & ATT-2B \\
\hline & & OESBs are wise actions; & ATT-3B \\
\hline
\end{tabular}

Table 3. The household energy-saving behavior (HESB) and office energy-saving behavior (OESB) checklist.

\begin{tabular}{|c|c|c|}
\hline Version & Scene & Item \\
\hline \multirow{4}{*}{ HESB-Q } & Kitchen & $\begin{array}{l}\text { Keep the fridge door closed after taking food. } \\
\text { Reduce the flame when boiling starts. } \\
\text { Cool down hot food before storing in the fridge. } \\
\text { Allow some space all around the fridge and keep the fridge far } \\
\text { from the heater. } \\
\text { Not overfill the fridge and allow some gaps between fridge and food. }\end{array}$ \\
\hline & Living room & $\begin{array}{l}\text { Turn off the television when not in use. } \\
\text { Close windows and doors when using heating or cooling system. } \\
\text { Set the heating system below } 20^{\circ} \mathrm{C} \text { in winter and set the air-condition } \\
\text { around } 25^{\circ} \mathrm{C} \text { in summer. } \\
\text { Set computer on energy-saving mode. }\end{array}$ \\
\hline & Bedroom & $\begin{array}{l}\text { Use natural light instead of artificial light in the daytime. } \\
\text { Use task lighting before plan to sleep. } \\
\text { Turn off light when sleeping. } \\
\text { Turn off the air-conditioning system when leaving the room. }\end{array}$ \\
\hline & Bathroom & $\begin{array}{l}\text { Take a shower rather than a bath. } \\
\text { Control the showering time. } \\
\text { Turn on the water heater only when necessary. }\end{array}$ \\
\hline \multirow[t]{2}{*}{ OESB-Q } & Office Desk & $\begin{array}{l}\text { Set computer on energy-saving mode when leaving for a short time and } \\
\text { switch off the computer when leaving for a long time. } \\
\text { Close windows and doors when using heating or cooling system. } \\
\text { Set the heating system below } 20^{\circ} \mathrm{C} \text { in winter and set the air-condition } \\
\text { around } 25^{\circ} \mathrm{C} \text { in summer. } \\
\text { Use task lighting for activities requiring a small amount of focus light. } \\
\text { Turn off air-conditioning and light when leaving the office. }\end{array}$ \\
\hline & Pantry & $\begin{array}{c}\text { Switch on the water heater only when necessary and turn it off } \\
\text { when not use. } \\
\text { Cool down hot food before storing in the fridge. } \\
\text { Turn off light when leaving. } \\
\text { Heat enough water without too much unused. }\end{array}$ \\
\hline
\end{tabular}

\subsection{Respondents Profile}

The study distributed 800 questionnaires in the two groups. A few participants declined to participate or filled in the questionnaire incompletely. In total, the researchers collected 753 responses, 683 (i.e., $90.70 \%$ ) of them were valid. There were 335 valid responses from Group A, where 168 were male (i.e., $50.51 \%$ ) and 167 were female (i.e. $49.85 \%$ ). Group B has a valid sample of 348: the numbers of male and female were 177 (i.e., 50.86\%) and 171 (i.e., 49.14\%), respectively. In Group A, 219 (i.e., 65.37\%) respondents held a bachelor or higher-level degree. There were 235 (i.e., $48.56 \%$ ) bachelor or higher-level degree holders in Group B. The annual income level of most participants ranged from CNY 50,000 to 150,000 per year. The respondent profile and the statistical data in $\mathrm{Xi}^{\prime}$ an 
and mainland China are compared in Table 4 in detail. The sociodemographic information of Xi'an city was found from the 2010 population census of the People's Republic of China [59] as well as the statistical communique of $\mathrm{Xi}^{\prime}$ an on national economic and social development in 2019 [60]. The national sociodemographic information comes from the 2010 population census of the People's Republic of China [59] and the People's Republic of China on national economic and social development in 2019 [61]. All the participants in this study had stable jobs. Thus, the percentages of adolescents and senior people are less than the national average level. Besides, the average income level of the participants was significantly higher than the national level for the same reason.

Table 4. Socio-demographic characteristics of respondents.

\begin{tabular}{|c|c|c|c|c|c|c|c|}
\hline \multirow{2}{*}{ Item } & \multirow{2}{*}{ Range } & \multicolumn{2}{|c|}{ Group A } & \multicolumn{2}{|c|}{ Group B } & \multirow{2}{*}{$\begin{array}{c}\text { Statistic Data (Xi'an) } \\
\text { Percentage }\end{array}$} & \multirow{2}{*}{$\begin{array}{c}\text { Statistic Data (China) } \\
\text { Percentage }\end{array}$} \\
\hline & & Frequency & Percentage & Frequency & Percentage & & \\
\hline \multirow{7}{*}{ Age } & $<18$ & 5 & $1.49 \%$ & 8 & $2.30 \%$ & $25.32 \%$ & $24.10 \%$ \\
\hline & $18-25$ & 70 & $20.90 \%$ & 67 & $19.25 \%$ & $10.62 \%$ & $9.56 \%$ \\
\hline & $26-30$ & 79 & $23.58 \%$ & 83 & $23.85 \%$ & $7.87 \%$ & $7.58 \%$ \\
\hline & $31-40$ & 92 & $27.46 \%$ & 88 & $25.29 \%$ & $16.12 \%$ & $16.14 \%$ \\
\hline & $41-50$ & 51 & $15.22 \%$ & 58 & $16.67 \%$ & $15.45 \%$ & $17.28 \%$ \\
\hline & $51-60$ & 33 & $9.85 \%$ & 35 & $10.06 \%$ & $12.26 \%$ & $12.01 \%$ \\
\hline & $>60$ & 5 & $1.49 \%$ & 9 & $2.59 \%$ & $12.37 \%$ & $13.32 \%$ \\
\hline \multirow{2}{*}{ Gender } & Male & 168 & $50.15 \%$ & 177 & $50.86 \%$ & $51.26 \%$ & $51.19 \%$ \\
\hline & Female & 167 & $49.85 \%$ & 171 & $49.14 \%$ & $48.74 \%$ & $48.81 \%$ \\
\hline \multirow{5}{*}{$\begin{array}{l}\text { Education } \\
\text { Level }\end{array}$} & $\begin{array}{l}\text { Secondary School } \\
\text { or Below }\end{array}$ & 27 & $8.06 \%$ & 24 & $6.90 \%$ & N/A & $\mathrm{N} / \mathrm{A}$ \\
\hline & $\begin{array}{l}\text { High School } \\
\text { or equivalent }\end{array}$ & 89 & $26.57 \%$ & 89 & $25.57 \%$ & $20.66 \%$ & $15.02 \%$ \\
\hline & $\begin{array}{c}\text { Bachelor's degree } \\
\text { or equivalent }\end{array}$ & 165 & $49.25 \%$ & 169 & $48.56 \%$ & \multirow{3}{*}{$22.00 \%$} & \multirow{3}{*}{$9.53 \%$} \\
\hline & $\begin{array}{c}\text { Master's degree } \\
\text { or equivalent }\end{array}$ & 52 & $15.52 \%$ & 62 & $17.82 \%$ & & \\
\hline & $\begin{array}{l}\text { Doctor's degree } \\
\text { or above }\end{array}$ & 2 & $0.60 \%$ & 4 & $1.15 \%$ & & \\
\hline \multirow{8}{*}{$\begin{array}{l}\text { Income Level } \\
\text { (CNY Per Year) }\end{array}$} & $<30,000$ & 48 & $14.33 \%$ & 54 & $15.52 \%$ & \multirow{8}{*}{$\begin{array}{l}\text { The average disposable } \\
\text { income of urban residents is } \\
41,850 \text { while for rural } \\
\text { residents is } 14,588 .\end{array}$} & \multirow{8}{*}{$\begin{array}{l}\text { The average disposable } \\
\text { income of urban residents is } \\
42,359 \text { while for rural } \\
\text { residents is } 16,021 .\end{array}$} \\
\hline & $30,000-50,000$ & 34 & $10.15 \%$ & 38 & $10.92 \%$ & & \\
\hline & $50,000-100,000$ & 93 & $27.76 \%$ & 83 & $23.85 \%$ & & \\
\hline & $100,000-150,000$ & 71 & $21.19 \%$ & 72 & $20.69 \%$ & & \\
\hline & $150,000-250,000$ & 41 & $12.24 \%$ & 48 & $13.79 \%$ & & \\
\hline & $250,000-300,000$ & 15 & $4.48 \%$ & 15 & $4.31 \%$ & & \\
\hline & $>300,000$ & 12 & $3.58 \%$ & 12 & $3.45 \%$ & & \\
\hline & N/A & 21 & $6.27 \%$ & 26 & $7.47 \%$ & & \\
\hline
\end{tabular}

\subsection{Data Analysis}

This study employed structural equation modelling (SEM) for data analysis. SEM consists of two types, namely covariance-based SEM and partial least squares SEM (PLS-SEM) [62]. As a useful statistical tool for testing the formulated hypotheses, PLS-SEM was selected in this study to quantify the impacts of different constructs [63]. PLS-SEM has been widely employed in behavioral sciences-related research with the ability to handle non-normal data and avoid many restrictive data assumptions. For example, Liu et al. [8] adopted PLS-SEM to investigate the psychological factors influencing HESBs. Another example is that Tan [64] employed PLS-SEM to predict sustainable real estate purchasing intention with personal values and attitudes. Nomura et al. [65] also revealed the psychological driving force behind household recycling behavior. This study employs the software Smart-PLS 3 as a tool for data analysis.

The analysis process involves two steps: (1) assess the measurement model and (2) evaluate the structural model $[8,66]$. For the measurement modeling, composite reliability $(\mathrm{CR})$, convergent validity $(\mathrm{CV})$ and discriminant validity (DV) are the common criteria to indicate the model's validity and reliability. Normally, a satisfactory value for CR varies between 0.7 to 0.9 [66]. CV can be assessed with the values of average variance extracted (AVE) and the measurement items loadings. 
AVE refers to a measure of the amount of variance which is captured by a latent construct in relation to the amount of variance due to measurement error [67]. The acceptable AVE value of each element should exceed 0.5 [63], while the measurement loading of a specific item should be larger than $0.4[8,68]$. DV assessment is used to confirm that each latent variable is not correlated with other latent variables [68]. The heterotrait-monotrait (HTMT) ratio is one of the common methods for DV measurement, and its index should not exceed $0.9[8,69]$. Using the bootstrap re-sampling technique, the path coefficients ( $t$-value) and levels of significance ( $p$ value), construct reliability and validity (CR and CV) and discriminant validity (DV) were generated in the structural model $[66,70]$. The analysis results are discussed in the succeeding sections.

\section{Results}

In this section, the study first shows the measurement modeling results to ensure all measurement items and constructs are statistically reliable and valid for modeling, which includes two steps: (1) the $\mathrm{CV}$ and CR assessment, and (2) the DV measurement. The study analyzes the factor loading of each item as well as AVE, CR, CV and heterotrait-monotrait (HTMT) ratio. Then, the study conducts the structural modeling and analysis.

\subsection{Group A: HESB}

Tables 5 and 6 illustrate the results of the measurement modeling. Table 5 pays attention to the factor loadings as well as to two criteria in the CV and CR assessment (i.e., AVE and CR). The data show that the measurement loadings of all items are greater than or equal to 0.614 (i.e., $>0.4$ ). Further, the AVEs and CRs of the constructs well met the statistical requirements. Besides, Table 6 focuses on the DV assessment results by illustrating the HTMT ratio. The result analysis suggests that the measurement in this study fulfills the discriminant validity requirements.

Subsequent to the measurement modeling process, this study then conducts the PLS structural modelling analysis and illustrates the analysis results in Table 7 . In addition to the statistical significance of the hypothesized relationships, the table also presents the sample mean and standard deviation (STDEV) of each relationship.

Table 5. The convergent validity (CV) and composite reliability (CR) assessment results of Group A.

\begin{tabular}{|c|c|c|c|c|}
\hline Constructs & Item & FL & AVE & Composite Reliability \\
\hline \multirow{3}{*}{ Attitude (ATT) } & ATT-1A & 0.644 & \multirow{3}{*}{0.586} & \multirow{3}{*}{0.810} \\
\hline & ATT-2A & 0.771 & & \\
\hline & ATT-3A & 0.862 & & \\
\hline \multirow{4}{*}{ Behavioral Intention (BI) } & HESBI-1 & 0.720 & \multirow{4}{*}{0.546} & \multirow{4}{*}{0.767} \\
\hline & HESBI-2 & 0.739 & & \\
\hline & HESBI-3 & 0.669 & & \\
\hline & HESBI-4 & 0.614 & & \\
\hline \multirow{2}{*}{ Extraversion (E) } & $\mathrm{E}-1 \mathrm{~A}$ & 0.867 & \multirow{2}{*}{0.785} & \multirow{2}{*}{0.865} \\
\hline & E-2A & 0.915 & & \\
\hline \multirow{2}{*}{ Openness (O) } & $\mathrm{O}-1 \mathrm{~A}$ & 0.884 & \multirow{2}{*}{0.656} & \multirow{2}{*}{0.788} \\
\hline & $\mathrm{O}-2 \mathrm{~A}$ & 0.728 & & \\
\hline \multirow{2}{*}{ Agreeableness (A) } & A-1A & 0.949 & \multirow{2}{*}{0.598} & \multirow{2}{*}{0.721} \\
\hline & A-2A & 0.712 & & \\
\hline \multirow{2}{*}{ Conscientiousness (C) } & C-1A & 0.887 & \multirow{2}{*}{0.685} & \multirow{2}{*}{0.832} \\
\hline & $\mathrm{C}-2 \mathrm{~A}$ & 0.751 & & \\
\hline \multirow{2}{*}{ Neuroticism (N) } & $\mathrm{N}-1 \mathrm{~A}$ & 0.844 & \multirow{2}{*}{0.705} & \multirow{2}{*}{0.821} \\
\hline & $\mathrm{N}-2 \mathrm{~A}$ & 0.824 & & \\
\hline
\end{tabular}

Note: FL refers to factor loading; AVE refers to average variance extracted; HESBI refers to household energy-saving behavioral intention. 
Table 6. Discriminant validity (DV) assessment results of Group A.

\begin{tabular}{cccccccc}
\hline & ATT & HESBI & A & C & E & N & O \\
\hline ATT & & & & & & & \\
HESBI & 0.745 & & & & & & \\
A & 0.539 & 0.762 & & & & & \\
C & 0.400 & 0.197 & 0.456 & & & & \\
E & 0.204 & 0.075 & 0.604 & 0.619 & & & \\
N & 0.405 & 0.558 & 0.711 & 0.548 & 0.730 & & \\
O & 0.524 & 0.430 & 0.558 & 0.316 & 0.527 & 0.463 & \\
\hline
\end{tabular}

Note: ATT refers to attitude towards HESB; HESBI refers to household energy-saving behavioral intention; A refers to Agreeableness; $\mathrm{C}$ refers to Conscientiousness; E refers to Extraversion; O refers to Openness; $\mathrm{N}$ refers to Neuroticism.

Table 7. Structural modeling analysis results of Group A.

\begin{tabular}{|c|c|c|c|c|c|}
\hline Hypothesis & $\beta$ & Sample Mean & STDEV & $t$-Value & $p$-Value \\
\hline $\mathrm{H}_{1}: \mathrm{A} \rightarrow \mathrm{HESB}$ ATT & 0.190 & 0.195 & 0.063 & 3.027 & $0.003^{* *}$ \\
\hline $\mathrm{H}_{2}: \mathrm{C} \rightarrow \mathrm{HESB}$ ATT & 0.045 & 0.050 & 0.070 & 0.647 & 0.518 \\
\hline $\mathrm{H}_{3}: \mathrm{O} \rightarrow$ HESB ATT & 0.236 & 0.238 & 0.062 & 3.840 & $<0.001^{* * *}$ \\
\hline $\mathrm{H}_{4}: \mathrm{E} \rightarrow \mathrm{HESB}$ ATT & -0.025 & -0.018 & 0.060 & 0.421 & 0.674 \\
\hline $\mathrm{H}_{5}: \mathrm{N} \rightarrow \mathrm{HESB}$ ATT & -0.154 & -0.152 & 0.073 & 2.107 & 0.035 * \\
\hline HESB ATT $\rightarrow$ HESBI & 0.367 & 0.383 & 0.061 & 6.067 & $<0.001^{* * *}$ \\
\hline
\end{tabular}

The results suggest that HESB attitude is an effective predictor of HESB intention, for the correlation between HESB attitude and intention is significant (i.e., $\beta=0.367, p<0.001$ ). There are only two personality traits positively correlated with HESB attitude, including Agreeableness and Openness. It seems that Openness presents the strongest contribution (i.e., $\beta=0.236, p<0.001$ ) to HESB attitude among the five personality traits. Besides, Agreeableness has a positive effect (i.e., $\beta=0.190$, $p=0.003$ ) on HESB attitude as well. On the contrary, Neuroticism shows a significant but negative relationship (i.e., $\beta=-0.154, p=0.035$ ) with HESB attitude. The analysis results indicate that the effect of Conscientiousness on HESB attitude is small and less significant (i.e., $\beta=0.045, p=0.518$ ). The negative influence of Extraversion on HESB attitude seems small and insignificant as well.

\subsection{Group B: OESB}

Tables 8 and 9 present the measurement modeling results of Group B. Similar to Table 5 in Section 4.1, Table 8 shows the factor loading of each item and the CV and CR assessment results. The factor loadings of the employed items vary between 0.708 and 0.949 and are significantly greater than 0.4. Further, the employed constructs show satisfactory AVE (i.e., no less than 0.5) as well as CR (i.e., between 0.7 and 0.9 ) levels. Table 9 presents the HTMT ratio of the constructs, which supports that the measurement meets the DV requirements.

Then, this study conducts the structural modeling analysis and illustrates the statistical significance of the hypothesized relationships in Table 10.

Similar to the HESB intention, the results indicate that OESB intention can be well predicted by OESB attitude. The relationship between OESB attitude and OESB intention is positive and significant (i.e., $\beta=0.587, p<0.001$ ). There are two personality traits positively contributing to OESB attitude as well: Agreeableness and Extraversion. Agreeableness presents a relatively strong and positive effect (i.e., $\beta=0.181, p=0.011$ ) on OESB attitude, while Extraversion presents a positive and significant relationship (i.e., $\beta=0.139, p=0.043$ ) with OESB attitude. By contrast, Neuroticism plays a negative role in OESB attitude. The relationship between Neuroticism and OESB attitude is negative but significant (i.e., $\beta=-0.133, p=0.042$ ). The contribution of Conscientiousness and Openness seems positive but less significant. 
Table 8. The CV and CR assessment results of Group B.

\begin{tabular}{ccccc}
\hline Constructs & Item & FL & AVE & Composite Reliability \\
\hline \multirow{3}{*}{ Attitude (ATT) } & ATT-1B & 0.888 & & \\
& ATT-2B & 0.907 & 0.724 & 0.887 \\
& ATT-3B & 0.748 & & \\
Behavioral Intention (BI) & OESBI-1 & 0.913 & 0.751 & 0.857 \\
& OESBI-2 & 0.818 & & \\
Extraversion (E) & E-1B & 0.712 & 0.693 & 0.816 \\
Openness (O) & E-2B & 0.938 & & 0.731 \\
Ogreeableness (A) & O-1B & 0.780 & 0.517 & \\
& O-2B & 0.966 & & 0.735 \\
Conscientiousness (C) & A-1B & 0.949 & 0.513 & 0.804 \\
\multirow{2}{*}{ Neuroticism (N) } & A-2B & 0.754 & & \\
& C-1B & 0.896 & 0.674 & 0.748 \\
\hline
\end{tabular}

Note: $\overline{\text { FL refers to factor loading; AVE refers to average variance extracted; OESBI refers to office energy-saving }}$ behavioral intention.

Table 9. DV assessment results of Group B.

\begin{tabular}{cccccccc}
\hline & ATT & OESBI & A & C & E & N & O \\
\hline ATT & & & & & & & \\
OESBI & 0.778 & & & & & & \\
A & 0.766 & 0.781 & & & & & \\
C & 0.266 & 0.107 & 0.461 & & & & \\
E & 0.276 & 0.102 & 0.682 & 0.389 & & & \\
N & 0.274 & 0.261 & 0.701 & 0.551 & 0.426 & & \\
O & 0.270 & 0.207 & 0.556 & 0.270 & 0.763 & 0.625 & \\
\hline
\end{tabular}

Note: ATT refers to attitude towards HESB; HESBI refers to household energy-saving behavioral intention; A refers to Agreeableness; $\mathrm{C}$ refers to Conscientiousness; E refers to Extraversion; O refers to Openness; $\mathrm{N}$ refers to Neuroticism.

Table 10. Structural modeling analysis results of Group B.

\begin{tabular}{|c|c|c|c|c|c|}
\hline Hypothesis & $\beta$ & Sample Mean & STDEV & $t$-Value & $p$-Value \\
\hline $\mathrm{H}_{6}: \mathrm{A} \rightarrow \mathrm{OESB}$ ATT & 0.181 & 0.179 & 0.071 & 2.538 & $0.011 *$ \\
\hline $\mathrm{H}_{7}: \mathrm{C} \rightarrow \mathrm{OESB}$ ATT & 0.034 & 0.043 & 0.061 & 0.555 & 0.579 \\
\hline $\mathrm{H}_{8}: \mathrm{O} \rightarrow \mathrm{OESB}$ ATT & 0.013 & 0.032 & 0.055 & 0.245 & 0.806 \\
\hline $\mathrm{H}_{9}: \mathrm{E} \rightarrow \mathrm{OESB}$ ATT & 0.138 & 0.139 & 0.068 & 2.022 & 0.043 * \\
\hline $\mathrm{H}_{10}: \mathrm{N} \rightarrow \mathrm{OESB}$ ATT & -0.133 & -0.139 & 0.065 & 2.038 & $0.042 *$ \\
\hline OESB ATT $\rightarrow$ OESBI & 0.587 & 0.587 & 0.050 & 11.681 & $<0.001^{* * *}$ \\
\hline
\end{tabular}

The analysis results suggest that two personality traits, Agreeableness and Neuroticism, play critical roles in general energy conservation behavior: those two traits are significantly related to both HESB and OESB attitude. However, Agreeableness plays a positive role in the energy-saving behavioral process, while the role Neuroticism plays is negative. Among all the traits, Openness represents the strongest predictor of HESB attitude. However, the effect of Openness on OESB attitude is small and less significant. Besides, Extraversion presents a significant correlation with OESB attitude, while the influence of Extraversion on HESB attitude seems less significant. The effect of Conscientiousness on both HESB and OESB attitude is insignificant. 


\section{Discussion}

\subsection{The Impacts of Personality Traits}

The results of the current study suggest that the influence of Agreeableness and Neuroticism on energy conservation behavioral attitudes and intentions less depends on the external environment. These two "energy-saving personality traits" can work as predictors reflecting overall energy-saving attitudes. However, the relationships between some personality traits, such as Openness and Extraversion, and energy-saving personality only become significant with some specific external environment. Those personality traits may predict the energy-saving potentials of individuals in some specific situations. The study finds that Agreeableness and Neuroticism are significantly correlated with both HESB and OESB attitudes. These findings indicate that the impacts of Agreeableness and Neuroticism on energy-saving attitude might not depend on the surrounding environment. The positive correlation between Agreeableness and energy-saving attitude is in line with previous studies on the personality basis of PEBs (such as $[15,25,27])$. Agreeable people are more likely to present stronger empathic concern [71] and tend to consider collective interests and others' feelings. Individuals with higher Agreeableness levels might extend their empathic concerns to energy-saving. This is also supported by Berenguer [72] and Luch et al. [46], whose findings suggested that empathic concerns work positively in the environmental protection behavioral process. Surprisingly, Neuroticism presents significant but negative relationships with both HESB and OESB attitudes. This finding suggests that neurotic people present a weaker energy conservation attitude in both the office and the family environment. Individuals with higher Neuroticism show higher tendency to present negative emotional characteristics, such as sensitivity, nervousness and insecurity [73]. Thus, emotional stability might play the role as the predictor of energy conservation intention. This is also supported by Chiang et al. [49] and Van Egeren [74], who believe that Neuroticism positively contributes to the external locus of control (ELC) while ELC is negatively related to PEB attitudes. People with stronger emotional uneasiness are more likely to be influenced by ELC.

The study results demonstrate a significant correlation between Extraversion and OESB attitude, which is consistent with some previous evidence that supports the positive correlation between Extraversion and OHPEB attitudes and intentions (such as [25] and [48]). However, the study also found that the effect of Extraversion on IESB attitude is small and less significant. Extroverts generally present stronger sociability [75]. Individuals with higher Extraversion tend to engage in specific behaviors to integrate into the collective. Previous studies also found that Extraversion is one of the predictors of country-level environmental engagement [30]. Further, Kamal and Barpanda [26] note that Extraversion bridges social aspiration and environmental concern. Compared with the office, the family environment emphasizes privacy. At home, people receive fewer expectations and evaluations from others, and do not need to perform special actions for social engagement. This might partially explain the reason why people with higher Extraversion present higher energy-saving potential than others at the office but not at home.

Openness only presents a significant correlation with HESB attitude. Openness reflects the degree of intellectual curiosity, creativity and a preference for novelty and variety of an individual. Therefore, people with a higher level of openness-to-experience are more natural to accept environmental protection concepts. Besides, people with higher openness are more likely to be interested in novel environmental-friendly technologies [41]. At home, more open individuals have more opportunities to practice different environmental protection solutions or install novel environmental protection technologies. This might explain the significant correlation between Openness and household energy-efficient technology installation attitudes in two studies in the UK [41] and China [42]. However, office facilities are relatively monotonous with complex rules. It could be difficult for people to apply novel energy-saving ideas to the office environment. This may limit the willingness of more open employees to save energy at the office. 
The results reveal that personality traits obviously influence the energy-saving process in both household and office environments. The contributions of some specific personality traits to the pro-environmental attitude are not dependent on the situation and environment. Those personality traits can well predict the overall environmental protection intentions as well as the potentials of individuals. However, some personality characteristics are only able to predict the pro-environmental behavior in some specific situations. In addition, the researchers found out and thus prospect that it would be valuable to customize environmental protection schemes in the future: the same strategies are not suitable to apply to each individual or in each situation. It would be better to develop specific informatic interventions according to the personality characteristics of targets as well as the surrounding environment. Although the evaluation of personality and other demographic characteristics of each individual is a challenge to decision-makers, the effectiveness and efficiency of those schemes would be highly strengthened by achieving the target for the individuals with the most substantial energy-saving potential and the targets who are able to save more with assistance. Besides, the findings in this study would provide references for behavior simulation in the built environment in further studies.

\subsection{Limitations and Further Studies}

This research has some limitations as well. First, the findings in this study cannot be generalized to the population in other settings. The field experiment in this study was conducted in Xi'an, China. Due to the different social and economic backgrounds, the results should be empirically validated with caution before applying in different contexts. Second, despite the efforts made by the researcher to maximize the potential respondents, the sample size for the study is relatively small. The sample sizes for the two groups were 335 and 348, respectively. Although the sample size meets the requirement of statistical data analysis, further studies would benefit from a larger sample size. Moreover, the selected study area is a typical urban area in a well-developed Chinese city, therefore the percentages of bachelor's or higher-level degree holders and high-income families in this study exceed the average level in China since the rural population constitutes approximately $45 \%$ in China. Follow-up studies are therefore recommended to take into account energy-saving studies in other regions and pay attention to rural areas, which are conducive to the comprehensiveness of the research. In addition, the authors recommend that future research would benefit from employing different personality inventories to avoid excessive two-variables-based latent constructs.

\section{Conclusions}

This study presents a field experiment in Xi'an, China to explore the personality basis of the individual difference between energy-saving attitudes in office and household environments. The SEM analysis results indicate that Agreeableness and Neuroticism are significantly correlated with energy-saving attitudes in both office and household environments. The finding suggests that the influence of these two personality traits on energy-saving attitude might not depend on the surrounding environment. By contrast, the external environment plays a more critical role in the relationship between energy-saving attitudes and the other two personality traits, Openness and Extraversion. Openness only positively contributes to energy-saving attitudes and intentions in the household environment, while Extraversion only presents a significant relationship to ones' energy-saving attitudes in the office. It is hoped that the findings would provide references for the energy-saving schemes as well as simulations in the future. The effectiveness of further energy-saving interventions would be much improved by targeting individuals with more energy-saving potentials. Besides, based on the findings in this study, further studies would explore the personality basis of the spillover effect of PEBs.

Author Contributions: Conceptualization, Q.-C.W. and Y.-X.W.; methodology, Q.-C.W.; software, Y.-X.W.; validation, Y.-X.W. and Y.-T.M.; formal analysis, Y.-X.W. and I.Y.J.; investigation, Y.-X.W. and Y.-T.M.; resources, Q.-C.W., I.Y.J. and X.L; data curation, I.Y.J.; writing-original draft preparation, Q.-C.W., Y.-X.W. and I.Y.J.; writing-review and editing, Q.-C.W., H.-H.W. and X.L.; visualization, I.Y.J. and Y.-T.M.; supervision, H.-H.W. 
and X.L.; project administration, H.-H.W. and X.L. All authors have read and agreed to the published version of the manuscript.

Funding: The research project is partially supported by the China Scholarship Council (CSC).

Acknowledgments: The authors would like to thank the CSC for financial support. Besides, the authors would like to thank Meng Ni from the Hong Kong Polytechnic University who guided the project. Further, the authors would like to further acknowledge Jia-Yu Chen, Rui-Zhen Hu, Hao-Zhe Li, Yi-Nuo Su, Josephine Yim, Ya-Ni Zhang, Fang Lee and Justin Foo from the University of Cambridge as well as Frankie Leung from Harvard University. The project would not have completed without their warm encourage and invaluable suggestions.

Conflicts of Interest: The authors declare no conflicts of interests.

\section{References}

1. Winzer, C. Conceptualizing energy security. Energy Policy 2012, 46, 36-48. [CrossRef]

2. Yu, C.R.; Guo, H.S.; Wang, Q.C.; Chang, R.D. Revealing the Impacts of Passive Cooling Techniques on Building Energy Performance: A Residential Case in Hong Kong. Appl. Sci. 2020, 10, 4188. [CrossRef]

3. Augutis, J.; Krikstolaitis, R.; Martisauskas, L.; Peciulyte, S. Energy security level assessment technology. Appl. Energy 2012, 97, 143-149. [CrossRef]

4. Ones, D.S.; Wiernik, B.M.; Dilchert, S.; Klein, R. Pro-environmental behavior. In International Encyclopedia of the Social \& Behavioral Sciences, 2nd ed.; Elsevier Inc.: Amsterdam, The Netherlands, 2015; pp. 82-88.

5. Chang, S.; Wang, Q.; Hu, H.; Ding, Z.; Guo, H. An NNwC MPPT-based energy supply solution for sensor nodes in buildings and its feasibility study. Energies 2019, 12, 101. [CrossRef]

6. Shen, M.; Lu, Y.; Kua, H.W.; Cui, Q. Eco-feedback delivering methods and psychological attributes shaping household energy consumption: Evidence from intervention program in Hangzhou, China. J. Clean. Prod. 2020, 265, 121755. [CrossRef]

7. Chang, R.; Wang, Q.; Ding, Z. How is the Energy Performance of Buildings Assessed in Australia?A Comparison between four Evaluation Systems. Int. J. Struct. Civil Eng. Res. 2019, 8, 133-137. [CrossRef]

8. Liu, X.; Wang, Q.; Wei, H.-H.; Chi, H.-L.; Ma, Y.; Jian, I.Y. Psychological and Demographic Factors Affecting Household Energy-Saving Intentions: A TPB-Based Study in Northwest China. Sustainability 2020, $12,836$. [CrossRef]

9. Wells, V.K.; Taheri, B.; Gregory-Smith, D.; Manika, D. The role of generativity and attitudes on employees home and workplace water and energy saving behaviours. Tour. Manag. 2016, 56, 63-74. [CrossRef]

10. Yazdanpanah, M.; Forouzani, M.; Abdeshahi, A.; Jafari, A. Investigating the effect of moral norm and self-identity on the intention toward water conservation among Iranian young adults. Water Policy 2016, 18, 73-90. [CrossRef]

11. Busic-Sontic, A.; Czap, N.V.; Fuerst, F. The role of personality traits in green decision-making. J. Econ. Psychol. 2017, 62, 313-328. [CrossRef]

12. Brick, C.; Lewis, G.J. Unearthing the "green" personality: Core traits predict environmentally friendly behavior. Environ. Behav. 2016, 48, 635-658. [CrossRef]

13. Bak, W. Personality predictors of anger. The role of FFM traits, shyness, and self-esteem. Pol. Psychol. Bull. 2016, 47, 373-382. [CrossRef]

14. Pavalache-Ilie, M.; Cazan, A.-M. Personality correlates of pro-environmental attitudes. Int. J. Environ. Health Res. 2018, 28, 71-78. [CrossRef] [PubMed]

15. Sun, Y.; Wang, S.; Gao, L.; Li, J. Unearthing the effects of personality traits on consumer's attitude and intention to buy green products. Nat. Hazards 2018, 93, 299-314. [CrossRef]

16. Johansson, M.V.; Heldt, T.; Johansson, P. The effects of attitudes and personality traits on mode choice. Transp. Res. Part A Policy Pract. 2006, 40, 507-525. [CrossRef]

17. Markowitz, E.M.; Goldberg, L.R.; Ashton, M.C.; Lee, K. Profiling the "pro-environmental individual": A personality perspective. J. Personal. 2012, 80, 81-111. [CrossRef]

18. Ribeiro, J.D.A.; Veiga, R.T.; Higuchi, A.K. Personality traits and sustainable consumption. Rev. Bras. Mark. 2016, 15, 297-313. [CrossRef]

19. Xie, X.; Lu, Y.; Gou, Z. Green building pro-environment behaviors: Are green users also green buyers? Sustainability 2017, 9, 1703. [CrossRef] 
20. Truelove, H.B.; Carrico, A.R.; Weber, E.U.; Raimi, K.T.; Vandenbergh, M.P. Positive and negative spillover of pro-environmental behavior: An integrative review and theoretical framework. Glob. Environ. Chang. 2014, 29, 127-138. [CrossRef]

21. Wang, Z.; Guo, D.; Wang, X.; Zhang, B.; Wang, B. How does information publicity influence residents' behaviour intentions around e-waste recycling? Resour. Conserv. Recycl. 2018, 133, 1-9. [CrossRef]

22. Bhushan, N.; Steg, L.; Albers, C. Studying the effects of intervention programmes on household energy saving behaviours using graphical causal models. Energy Res. Social Sci. 2018, 45, 75-80. [CrossRef]

23. Larson, L.R.; Stedman, R.C.; Cooper, C.B.; Decker, D.J. Understanding the multi-dimensional structure of pro-environmental behavior. J. Environ. Psychol. 2015, 43, 112-124. [CrossRef]

24. Tudor, T.; Barr, S.; Gilg, A. A tale of two locational settings: Is there a link between pro-environmental behaviour at work and at home? Local Environ. 2007, 12, 409-421. [CrossRef]

25. Tang, C.M.F.; Lam, D. The role of extraversion and agreeableness traits on Gen Y's attitudes and willingness to pay for green hotels. Int. J. Contemp. Hosp. Manag. 2017, 29, 607-623. [CrossRef]

26. Kamal, A.; Barpanda, S. Factors influencing the energy consumption behavior pattern among the Indian higher education institution students. In Proceedings of the 2017 International Conference on Technological Advancements in Power and Energy (TAP Energy), Kollam, India, 21-23 December 2017; pp. 1-6.

27. Shen, M.; Lu, Y.; Tan, K.Y. Big Five Personality Traits, Demographics and Energy Conservation Behaviour: A Preliminary Study of Their Associations in Singapore. Energy Procedia 2019, 158, 3458-3463. [CrossRef]

28. Phares, E.J. Introduction to Personality; Scott, Foresman \& Co.: Glenview, IL, USA, 1988.

29. Balderjahn, I. Personality variables and environmental attitudes as predictors of ecologically responsible consumption patterns. J. Bus. Res. 1988, 17, 51-56. [CrossRef]

30. Milfont, T.L.; Sibley, C.G. The big five personality traits and environmental engagement: Associations at the individual and societal level. J. Environ. Psychol. 2012, 32, 187-195. [CrossRef]

31. Passafaro, P.; Cini, F.; Boi, L.; D’Angelo, M.; Heering, M.S.; Luchetti, L.; Mancini, A.; Martemucci, V.; Pacella, G.; Patrizi, F. The "sustainable tourist": Values, attitudes, and personality traits. Tour. Hosp. Res. 2015, 15, 225-239. [CrossRef]

32. Shen, M.; Lu, Y.; Wei, K.H.; Cui, Q. Prediction of household electricity consumption and effectiveness of concerted intervention strategies based on occupant behaviour and personality traits. Renew. Sustain. Energy Rev. 2020, 127, 109839. [CrossRef]

33. Robinson, O.C.; Lopez, F.G.; Ramos, K. Parental antipathy and neglect: Relations with Big Five personality traits, cross-context trait variability and authenticity. Personal. Individ. Differ. 2014, 56, 180-185. [CrossRef]

34. Gosling, S.D.; Rentfrow, P.J.; Swann, W.B., Jr. A very brief measure of the Big-Five personality domains. J. Res. Personal. 2003, 19, 139-152. [CrossRef]

35. Lay, C.; Kovacs, A.; Danto, D. The relation of trait procrastination to the big-five factor conscientiousness: An assessment with primary-junior school children based on self-report scales. Personal. Individ. Differ. 2020, 25, 187-193.

36. Bergmann, N.; Schacht, S.; Gnewuch, U.; Mädche, A. Understanding the Influence of Personality Traits on Gamification: The Role of Avatars in Energy Saving Tasks. In Proceedings of the 38th International Conference on Information Systems (ICIS), Seoul, South Korea, 10-13 December 2017.

37. Komatsu, H.; Nishio, K.-I. An experimental study on motivational change for electricity conservation by normative messages. Appl. Energy 2015, 158, 35-43. [CrossRef]

38. Poškus, M.S.; Žukauskienė, R. Predicting adolescents' recycling behavior among different big five personality types. J. Environ. Psychol. 2017, 54, 57-64. [CrossRef]

39. Kvasova, O. The Big Five personality traits as antecedents of eco-friendly tourist behavior. Personal. Individ. Differ. 2015, 83, 111-116. [CrossRef]

40. Pavalache-Ilie, M.; Cazan, A. Measuring ecological attitudes in a Romanian context. Bull. Transilv. Univ. Bras. 2016, 9, 85-90.

41. Busic-Sontic, A.; Brick, C. Personality trait effects on green household installations. Collabra Psychol. $2018,4$. [CrossRef]

42. He, P.; Veronesi, M. Personality traits and renewable energy technology adoption: A policy case study from China. Energy Policy 2017, 107, 472-479. [CrossRef]

43. Swami, V.; Chamorro-Premuzic, T.; Snelgar, R.; Furnham, A. Personality, individual differences, and demographic antecedents of self-reported household waste management behaviours. J. Environ. Psychol. 2011, 31, 21-26. [CrossRef] 
44. Zhang, Y.; Wu, S.; Rasheed, M.I. Conscientiousness and smartphone recycling intention: The moderating effect of risk perception. Waste Manag. 2020, 101, 116-125. [CrossRef]

45. White, K.M.; Hyde, M.K. The role of self-perceptions in the prediction of household recycling behavior in Australia. Environ. Behav. 2012, 44, 785-799. [CrossRef]

46. Luchs, M.G.; Mooradian, T.A. Sex, personality, and sustainable consumer behaviour: Elucidating the gender effect. J. Consum. Policy 2012, 35, 127-144. [CrossRef]

47. Yazdanpanah, M.; Hadji Hosseinlou, M. The role of personality traits through habit and intention on determining future preferences of public transport use. Behav. Sci. 2017, 7, 8. [CrossRef] [PubMed]

48. Kim, J.; Schmöcker, J.-D.; Bergstad, C.J.; Fujii, S.; Gärling, T. The influence of personality on acceptability of sustainable transport policies. Transportation 2014, 41, 855-872. [CrossRef]

49. Chiang, Y.-T.; Fang, W.-T.; Kaplan, U.; Ng, E. Locus of control: The mediation effect between emotional stability and pro-environmental behavior. Sustainability 2019, 11, 820. [CrossRef]

50. Tiefenbeck, V.; Degen, K.; Tasic, V.; Goette, L.; Staak, T. On the Effectiveness of Real-time Feedback: The influence of Demographics, Attitudes and Personality Traits. Final report to the Swiss Fedearl Office of Energy, Bern. 2014. Bits Energy Lab. Zur. 2014, 2, 1-50.

51. Sun, Z.-J.; Zhu, L.; Liang, M.; Xu, T.; Lang, J.-h. The usability of a WeChat-based electronic questionnaire for collecting participant-reported data in female pelvic floor disorders: A comparison with the traditional paper-administered format. Menopause 2016, 23, 856-862. [CrossRef]

52. Milfont, T.L.; Milojev, P.; Greaves, L.M.; Sibley, C.G. Socio-structural and psychological foundations of climate change beliefs. N. Zealand J. Psychol. 2015, 44, 17-30.

53. Shen, M.; Cui, Q.; Fu, L. Personality traits and energy conservation. Energy Policy 2015, 85, 322-334. [CrossRef]

54. Kingsford Owusu, E.; Chan, A.P. Barriers Affecting Effective Application of Anticorruption Measures in Infrastructure Projects: Disparities between Developed and Developing Countries. J. Manag. Eng. 2018, 35, 04018056. [CrossRef]

55. Menardo, E.; Brondino, M.; Pasini, M. Adaptation and psychometric properties of the Italian version of the Pro-Environmental Behaviours Scale (PEBS). Environ. Dev. Sustain. 2019, 21, 1-24. [CrossRef]

56. Lavelle-Hill, R.E.; Smith, G.; Bibby, P.; Clarke, D.; Goulding, J. Psychological and Demographic Predictors of Plastic Bag Consumption in Transaction Data. In Proceedings of the 3rd World Conference on Personality, Hanoi, Vietnam, 2-6 April 2019.

57. Carciofo, R.; Yang, J.; Song, N.; Du, F.; Zhang, K. Psychometric evaluation of Chinese-language 44-item and 10-item big five personality inventories, including correlations with chronotype, mindfulness and mind wandering. PLoS ONE 2016, 11, e0149963. [CrossRef] [PubMed]

58. Peng, K.-H.; Liou, L.-H.; Chang, C.-S.; Lee, D.-S. Predicting personality traits of Chinese users based on Facebook wall posts. In Proceedings of the 2015 24th Wireless and Optical Communication Conference (WOCC), Taipei, Taiwan, 23-24 October 2015; pp. 9-14.

59. China, N.B.o.S.o. The 2010 Population Census of the People's Republic of China; Bureau, N.S., Ed.; National Bureau of Statistics of China: Beijing, China, 2010.

60. Xi'an, T.S.B.o. Statistical Communique of Xi'an on National Economic and Social Development in 2019; X'an Municipal Statistics Bureau: Xi'an, China, 2019.

61. China, N.B.o.S.o. Statistical Communique of the People's Republic of China on National Economic and Social Development in 2019; National Bureau of Statistics of China: Beijing, China, 2020.

62. Hair, J.F.; Ringle, C.M.; Sarstedt, M. PLS-SEM: Indeed a silver bullet. J. Mark. Theory Pract. 2011, 19, $139-152$. [CrossRef]

63. Owusu, E.K.; Chan, A.P.; Hosseini, M.R. Impacts of anti-corruption barriers on the efficacy of anti-corruption measures in infrastructure projects: Implications for sustainable development. J. Clean. Prod. 2020, 246, 119078. [CrossRef]

64. Tan, T.H. Use of structural equation modeling to predict the intention to purchase green and sustainable homes in Malaysia. Asian Soc. Sci. 2013, 9, 181. [CrossRef]

65. Nomura, H.; Takahashi, Y.; Yabe, M. Psychological driving forces behind households' behaviors toward municipal organic waste separation at source in Vietnam: A structural equation modeling approach. J. Mater. Cycles Waste Manag. 2017, 19, 1052-1060. 
66. Yen, Y.; Wang, Z.; Shi, Y.; Xu, F.; Soeung, B.; Sohail, M.T.; Rubakula, G.; Juma, S.A. The predictors of the behavioral intention to the use of urban green spaces: The perspectives of young residents in Phnom Penh, Cambodia. Habitat Int. 2017, 64, 98-108. [CrossRef]

67. Afthanorhan, W. A comparison of partial least square structural equation modeling (PLS-SEM) and covariance based structural equation modeling (CB-SEM) for confirmatory factor analysis. Int. J. Eng. Sci. Innov. Technol. 2013, 2, 198-205.

68. Hair, J.F.; Ringle, C.M.; Sarstedt, M. Partial least squares structural equation modeling: Rigorous applications, better results and higher acceptance. Long Range Plan. 2013, 46, 1-12. [CrossRef]

69. Henseler, J.; Ringle, C.M.; Sarstedt, M. A new criterion for assessing discriminant validity in variance-based structural equation modeling. J. Acad. Mark. Sci. 2015, 43, 115-135. [CrossRef]

70. Wang, D.; Brown, G.; Liu, Y.; Mateo-Babiano, I. A comparison of perceived and geographic access to predict urban park use. Cities 2015, 42, 85-96. [CrossRef]

71. Graziano, W.G.; Habashi, M.M.; Sheese, B.E.; Tobin, R.M. Agreeableness, empathy, and helping: A person $\times$ situation perspective. J. Personal. Soc. Psychol. 2007, 93, 583. [CrossRef] [PubMed]

72. Berenguer, J. The effect of empathy in proenvironmental attitudes and behaviors. Environ. Behav. 2007, 39, 269-283. [CrossRef]

73. Costa, P.T.; McCrae, R.R. Influence of extraversion and neuroticism on subjective well-being: Happy and unhappy people. J. Personal. Soc. Psychol. 1980, 38, 668. [CrossRef]

74. Van Egeren, L.F. A cybernetic model of global personality traits. Personal. Soc. Psychol. Rev. 2009, 13, 92-108. [CrossRef] [PubMed]

75. Saboor, A.; Arfeen, M.I.; Mohti, W. Sociability Impact on Learner's Personality in Classroom and E-learning Environments: A Comparative Analysis to Help HRM Decisions. J. Indep. Stud. Res. Manag. Soc. Sci. Econ. 2017, 15, 78-90. [CrossRef]

(C) 2020 by the authors. Licensee MDPI, Basel, Switzerland. This article is an open access article distributed under the terms and conditions of the Creative Commons Attribution (CC BY) license (http://creativecommons.org/licenses/by/4.0/). 